\title{
Do Not Resuscitate (DNR) Argumentative Essay
}

Muhand Burghal $\mathbf{H}^{1^{*}}$ and Majd Maryyan ${ }^{2}$

${ }^{1}$ Senior Nurse in University of Jordan Hospital, Amman, Jordan

${ }^{2}$ Faculty of Nursing, The Hashemite University, Zarqa, Jordan

*Corresponding author: Muhand Burghal H, MSN, RN, Senior Nurse in University of Jordan Hospital, Amman, Jordan, Tel: 00971565888449; E-mail: muhand_hamada@yahoo.com

Rec date: November 06, 2017; Acc date: November 11, 2017; Pub date: November 18, 2017

Copyright: ( 2017 Burghal M, et al. This is an open-access article distributed under the terms of the Creative Commons Attribution License, which permits unrestricted use, distribution, and reproduction in any medium, provided the original author and source are credited.

\begin{abstract}
Patients with terminal cancer suffering from many physiological and psychological signs and symptoms that affected on quality of life. When the cancer patient could not be cured, the objective of treatment is to enhance human dignity and prevent needless suffering from unnecessary treatments. As result, DNR orders have become an integral part of the care of the terminally ill patient. Although DNR increased over decades but still DNR concept considering one of most common ethical and legal dilemma. The purpose of this argumentative essay to identify literature and to support current researcher's opinion about proppant to DNR; also taking into consideration the legal and ethical points of view of opponents and proponents. Argumentative essay is type of writing that requires author to investigate, collect and evaluate a phenomenon either proponent or opponent. Legally, Taiwan, Italy and Israel considered the use of DNR order illegal. While other countries such as United States, United Kingdom, Spain, French, Norway and Netherlands considered the DNR order for terminally ill patients as a legal action. Ethically, the religion and culture play an important two factors in acceptance to DNR order like Islam that support DNR under certain conditions such as, brain death, on other hand, there is religion such as Jewish and cultures opponent activate DNR order.
\end{abstract}

Keywords: Do not resuscitate; Argumentative essay

\section{Introduction}

Patients with advance cancer often experience many of physiological and psychological symptoms that affect quality of life [1]. However, $50 \%$ of patients with advance cancer aren't cured and have poor survival rate after cardiopulmonary arrest $[2,3]$. The survival rate after twenty-four hours from successful cardiopulmonary resuscitation (CPR) is only 9.2\% [4]. So, there is debate about usage of CPR among patients with terminal cancer. As result, over decade's significant effort have been made to activate use of DNR orders in patients with advanced cancer [5].

DNR is a written medical order that document patient decision about his or her desire to avoid aggressive and futile CPR [6]. However, the core of completing DNR order is to allow patient to die with dignity and prevent needless suffering from unnecessary treatments [7]. DNR order still has considering ethical dilemma that facing health care providers especially nursing [8]. Because of nursing spend most of their time bedside patients in hospital and home, so they can play important role in advocating patients to understand DNR order through effective communication by discerning their beliefs, values and wishes regard to decision-making.

However, few studies have been discussed and published in Arab and Muslim countries about DNR order [9]. On other hand, Western countries have been extensively published studies about DNR [10]. Argumentative essay is type of writing that requires author to examine a topic; gathering data, generate and evaluate evidence and establish a position on the topic in a concise manner [11]. In this kind of essay, we not only give information but also present an argument with the supporting ideas and opposing ideas of an argumentative issue. The purpose of this paper to write an argumentative essay to identify literature and to support current researcher's opinion about proppant to DNR; also taking into consideration the legal and ethical points of view of opponents and proponents.

\section{Background}

More than thirty years ago, the first hospital policies about DNR were published in the medical literatures [12]. Since that time, DNR orders still generate many ethical and legal controversies, despite efforts to help patients, families, and decision-makers make informed choices. This paper presents the current literature on obstacles that faced nurses to assist the patients in understanding goals of care and making the decision to have DNR orders written from both legal and ethical sides.

Globally, in western countries like United States, Finland, Sweden and Germany, DNR orders are common place in clinical practice [13]. However, this practice isn't yet fully understood in many of countries in Middle East [9]. The religion and culture are two important factors in the perception of society about DNR orders [14].

The decision to take the DNR protocol for patients with end stage cancer is one of the most important issues influencing the relationship between the medical team and the patients' caregivers. Mostly, DNR agreement most often being proposed by doctors, however, the exclusion of nurses from the DNR decision-making process make it reflect negatively to consult and support the patients and their family [15]. So, nurses must be involved in the planning as well as the implementation of DNR decisions [16]. 


\section{Legal Arguments}

\section{Opponent}

Around the world, still there is confusion about the meaning of DNR and how they have to be followed by care systems legally [17]. In, Taiwan, using DNR order for patients with terminal cancer or terminal ill is illegal, based on their culture, Taiwan citizens prefer that their loved ones exhale their last breath at home because it brings good fortune to future descendants [18].

Moreover, Italy believed on contrast DNR order, this issue is still being considered by the guidelines of the Società Italiana di Anestesia Analgesia Rianimazione e TerapiaIntensiva, but no law has been passed as of yet [19]. The Middle Eastern countries, particularly Israel, DNR is still illegal, based on The Jewish religion, rather than considering the dying event as a potentially reversible medical emergency, is thought of as an uninterrupted, peaceful transition from life to death [20].

\section{Proponent}

The use DNR orders have increased over the past decade [21]. According to Saczynski and hercollgues in their study, DNR order was a significant increased from 9\% in 2001 to 55\% in 2007 respectively and this is due to the increased awareness of patient and their families that reflect acceptance about end of life and DNR order [22].

The decision DNR was first legalized in the United States since 1980 by American Medical Association, it was emphasized that CPR was performed for the prevention of a sudden or unexpected death not the treatment of a terminal, irreversible illness [23].

Also, in Europe countries such as United Kingdom, French, Norway and Netherlands, DNR have legal force when assessed as valid and applicable, but there are several differences in the modality of surrogate designations and their decisional authority $[17,24,25]$.

There are no special guidelines for DNR in Middle East countries especially in the Muslim countries. Just Saudi Arabia has organized and completed a guideline based on the Religious fatwa and the implementation of this guideline is legally required [9].

\section{Ethical Arguments}

\section{Opponent}

DNR order still has considering ethical dilemma that facing decision maker, cultural and health care providers especially nursing. The religion and culture are two important factors in the perception of society about DNR orders [14].

Cohen described the DNR as "threatening" which evoke perception of coldness and hardness [26]. however, there is a large part of the population has strong ethnic and religious beliefs against DNR, and believed that death does not happen apart from by God's authorization and should make as possible as can to increase patient's survival with dignity [6].

DNR among health care providers especially nursing still not appropriate, according to Mogadasian and his colleagues in their study that investigate the attitude of Iranian nurses towards DNR orders and they conclude there is a negative attitude among Iranian nurses towards in many aspects of DNR orders regardless of their religious sects [7]. Furthermore, nurses in oncology ward can have very special relationships with patients, because of frequent treatment, they meet over a long period of time, maybe months or even year so DNR order among those patients may reflect minimizing quality of care and not important [27].

\section{Proponent}

In terminal cancer patients, it has been consistently shown unfavorable outcomes of CPR [15]. In this setting, CPR has been described as harmful for patients and patient's families, such as physical and Psychological suffering, loss of dignity, survival with unacceptable quality of life, and increasing family suffering, so DNR status is appropriate for the majority of advanced cancer patients.

For every ethical dilemma, Islamic juridical tradition seeks to address and accommodate the demands of justice and public good, according to Islamic instructions, human life should be respected, saved, and preserved. Based on this, Muslim health care professionals should do whatever possible to save patients' lives. Muslim scholars have allowed the use of DNR orders under certain conditions that do not contravene Islamic instructions [28].

The American Nurses Association (ANA) supports patients' rights to self-determination to avoid any aggressive intervention to resuscitate and die with dignity [16]. In addition, they recommended and support clinical nurses to innate DNR discussions with patients in terminal stage and their families and significant others as soon as possible to prevent suffering for many dying patients who experience cardio-pulmonary arrest.

As a summary, the DNR is debatable ethical and legal issues in the world. Also, there is different opinion about DNR order either proponent or opponent. Legally, Taiwan, Italy and Israel considered the use of DNR order illegal. While other countries such as United States, United Kingdom, Spain, French, Norway and Netherlands considered the DNR order for terminally ill patients as a legal action. Ethically, the religion and culture play an important two factors in acceptance to DNR order like Islam that support DNR under certain conditions such as, brain death, on other hand, there is religion such as Jewish and cultures opponent activate DNR order. But this argumentative paper illustrates to support author about proppant to do not resuscitate.

\section{Argumentative Statement}

DNR is not new concept but it is controversial concept that possessed legal and ethical tension about ending the life of terminally cancer patients. The author supports DNR order to preserve dignity and to prevent needless suffering from unnecessary treatments. In addition, there is a call to limit life-sustaining treatment because of a lack of resources; an issue that is especially pertinent in developing countries.

\section{Legal defense}

The decision of DNR legalized in many countries with patients in terminal cancer. It was emphasized that use DNR with patient in terminal cancer un-useful and increase suffering for patients and their families. Explicit DNR policies soon followed, and the patients' right to self-determination was promoted. The American Nurses Association (ANA) advocate patients' rights to self-determination [16]. This right includes the right to a natural death without any resuscitative efforts. In addition, the ANA in nursing: scope and standards of practice 
support nursing care for the patients that protect their autonomy, dignity, and rights [29].

\section{Ethical defense}

In Jordan, where Islamic culture governs aspects of daily life. Islam instructions, everyone will face death, and does not happen except by God's permission, as dictated in the Holy Qur'an. Nevertheless, Muslim's health-care providers must do everything possible to prevent early death and increase survival. Islam does not recognize a patient's right to die voluntarily because life is a divine trust and cannot be terminated by any form of active or passive. So, Islam allowed the use of DNR orders under certain of condition, such as brain damage which is caused by irreversible damage and there is nothing to do. Also, to provide comfort so that death can come as quickly and comfortably as possible.

In Islamic ethics an individual's welfare is intimately linked with his or her family and community. Accordingly, the principle of autonomy (which affords the individual liberty and capacity to make a decision without coercion) is not invoked to determine a sequence of action in matters related to end-of-life decisions. Whether or not a doctor can prolong life by introducing aggressive invasive intervention without causing further harm is a joint decision made by all associated with the patient. In some cases, the matter is even referred to the religious leaders, who provide prescriptive rulings for the families' consideration.

The current researcher is support DNR order among patient with advance cancer. Decisions about DNR status are often made in haste, under stressful situations, and by ill and fearful patients as they face hospital admission. The patients with poor prognosis and suffering from terminal disease, they should innate DNR/AND discussions as soon as possible to avoid needless suffering from unnecessary treatments and to allow patient to die with dignity.

Mostly, the physician and nursing are responsible for decide on a DNR order in consultation with the patient and/or the patient's relatives. We should have adopted guidelines for how decisions on a DNR should be made. The current researcher articulates the following course action and recommendation to take action on the DNR issue:

DNR order should be documented in a safe manner, that wards should have a common and clear terminology and updated periodically to reflect changes in the patient's condition.

Discussion of DNR status should be included whenever goals of treatment, such as benefits versus the burdens of treatment and comfort and symptom palliation.

The patients and their families should be involved in making decisions about DNR order.

Clinical nurses should be actively participating in timely and frequent discussions about goals of care and initiate DNR discussions with patients and their families.

The current researcher advocates to have clear polices in health care organization to increase institutional support for nurses.

DNR order needs to be supported by governmental and organizational policies.

Furthermore, the current researcher advocate involved nurses in planning and implementation of DNR decisions. Nursing should be actively participating in developing DNR polices within health care organization where they work. Also, researcher support nurses to explore all facets of the DNR process to build a foundation for evidence-based practice

The current researcher supports the patient's right for selfdetermination. The right includes the right for patient to natural death without CPR or any procedure to resuscitate. The nurses play major role in DNR decisions making by support and advocate for patients with terminal cancer to innate DNR by communication and discussion the benefit versus burden.

\section{Summary and Conclusion}

In summary, the DNR order considering dilemma that facing patient, patient's family and health care providers especially nursing. The purpose of this paper was to write an argumentative essay to support the use of DNR for terminally ill patients taking into consideration the legal and ethical points of view of both opponents and proponents.

Legally, some of countries considered DNR illegally such as Taiwan, Italy and Israel, on other hand there are many countries considered DNR order legally such as United States, United Kingdom, Spain, French, Norway and Netherlands. Ethically, religions and culture are most important factor to accept DNR order. Islam support DNR order in certain condition, on other hand Jewish against DNR.

The current researcher is with the DNR order with patient in end stage disease especially cancer patients. Nurses are playing important role in DNR decision process through advocate, communication and support patients. Nurses should utilize the researches and education to build a foundation for evidence-based practice and build clear polices in health care organization to support DNR order.

\section{References}

1. Kurucová R, Žiaková K, Gurková E, Šrámeková G (2015) Occurrence of annoying symptoms of patients with cancer. Central European Journal of Nursing.

2. Bakitas M, Lyons KD, Hegel MT, Balan S, Brokaw FC, et al. (2009) Effects of a palliative care intervention on clinical outcomes in patients with advanced cancer: the Project ENABLE II randomized controlled trial. JAMA 302: 741-749.

3. Reisfield GM, Wallace SK, Munsell MF, Webb FJ, Alvarez ER, et al. (2006) Survival in cancer patients undergoing in-hospital cardiopulmonary resuscitation: a meta-analysis. Resuscitation 71: 152-160.

4. Myrianthefs P, Kalafati M, Lemonidou C, Minasidou E, Evagelopoulou P, et al. (2003) Efficacy of CPR in a general, adult ICU. Resuscitation 57: 43-48.

5. Kizawa Y, Tsuneto S, Hamano J, Nagaoka H, Maeno T, et al. (2013) Advance directives and do-not-resuscitate orders among patients with terminal cancer in palliative care units in Japan: a nationwide survey. American Journal of Hospice and Palliative Medicine 30: 664-669.

6. Santonocito C, Ristagno G, Gullo A, Weil MH (2013) Do-not-resuscitate order: a view throughout the world. Journal of Critical Care 28: 14-21.

7. Mogadasian S, Abdollahzadeh F, Rahmani A, Ferguson C, Pakanzad F, et al. (2014) The attitude of Iranian nurses about do not resuscitate orders. Indian Journal of Palliative Care 20: 21.

8. Al Khalaileh M (2014) Jordanian critical care nurses' attitudes toward and experiences of do not resuscitate orders. International Journal of Palliative Nursing 20: 403-408.

9. Gouda A, Al-Jabbary A, Fong L (2010) Compliance with DNR policy in a tertiary care center in Saudi Arabia. Intensive Care Medicine 36: 2149-2153. 
Citation: Burghal MH, Maryyan M (2017) Do Not Resuscitate (DNR) Argumentative Essay. Clin Med Biochem 3: 136. doi:

10. Sprung CL, Maia P, Bulow HH, Ricou B, Armaganidis A, et al. (2007) The importance of religious affiliation and culture on end-of-life decisions in European intensive care units. Intensive Care Medicine 33: 1732-1739.

11. Baker, Brizee, Angeli (2013) Argumentative Essays. Retrieved from https://owl.english.purdue.edu

12. Burns JP, Edwards J, Johnson J, Cassem NH, Truog RD (2003) Do-notresuscitate order after 25 years. Critical Care Medicine 31: 1543-1550.

13. Loertscher L, Reed DA, Bannon MP, Mueller PS (2010) Cardiopulmonary resuscitation and do-not-resuscitate orders: a guide for clinicians. The American Journal of Medicine 123: 4-9.

14. Huang CH, Hu WY, Chiu TY, Chen CY (2008) The practicalities of terminally ill patients signing their own DNR orders-a study in Taiwan. Journal of Medical Ethics 34: 336-340.

15. Wang Z, Li YS, Zhao N, Yang JJ, Tu HY, et al. (2016) Do-not-resuscitate orders among advanced-stage Chinese lung cancer patients who died in hospital. Supportive Care in Cancer 24: 1763-1769.

16. American Nurses Association (2012) Nursing care and do not resuscitate (DNR) and allow natural death (AND) decisions.

17. Silveira MJ, Kim SY, Langa KM, Lautrette A, Peigne V, et al. (2010) Advance directives and surrogate decision making before death. New England Journal of Medicine 363: 295-296.

18. Jaing TH, Tsay PK, Fang EC, Yang SH, Chen SH, et al. (2007) "Do-notresuscitate" orders in patients with cancer at a children's hospital in Taiwan. Journal of Medical Ethics 33: 194-196.

19. van Delden JJ, Löfmark R, Deliens L, Bosshard G, Norup M, et al. (2006) Do-not-resuscitate decisions in six European countries. Critical Care Medicine 34: 1686-1690.

20. Edin MG (2007) Cardiopulmonary resuscitation in the frail elderly: clinical, ethical and halakhic issues. The Israel Medical Association Journal: IMAJ 9: 177-179.
21. Adams DH, Snedden DP (2006) How misconceptions among elderly patients regarding survival outcomes of inpatient cardiopulmonary resuscitation affect do-not-resuscitate orders. The Journal of the American Osteopathic Association 106: 402-404.

22. Saczynski JS, Gabbay E, McManus DD, McManus R, Gore JM, et al. (2012) Increase in the proportion of patients hospitalized with acute myocardial infarction with do-not-resuscitate orders already in place between 2001 and 2007: a nonconcurrent prospective study. Clinical Epidemiology 4: 267.

23. Hughes SS (2001) Making dollars out of DNA: the first major patent in biotechnology and the commercialization of molecular biology, 1974-1980. ISIS 92: 541-575.

24. Seymour J, Almack K, Kennedy S (2010) Implementing advance care planning: a qualitative study of community nurses' views and experiences. BMC Palliative Care 9: 4.

25. Mjåset C, Gulbrandsen P, Rønning OM, Thommessen B (2008) Before and after implementation of do-not-resuscitate orders in a stroke unit. Tidsskrift for den Norske Laegeforening: Tidsskrift for Praktisk Medicin, Ny Raekke 128: 2819-2822.

26. Cohen RW (2004) A tale of two conversations. The Hastings Center Report 34: 49.

27. Pettersson M, Hedström M, Höglund AT (2014) Striving for good nursing care: Nurses' experiences of do not resuscitate orders within oncology and hematology care. Nursing Ethics 21: 902-915.

28. Saiyad S (2009) Do not resuscitate: a case study from the Islamic viewpoint. Journal of the Islamic Medical Association of North America.

29. American Nurses Association (2015) Official ANA Position Statements. 